\title{
Um olhar sobre a "vivência" através do seu autor: conceitos e traduções na obra de Vigotski
}

\author{
Daniel Luiz Poio Roberti ${ }^{\text {Prid }, \star}$ \\ Universidade Federal Fluminense, Angra dos Reis, RJ, Brasil
}

Resumo

Quase 80 anos depois da morte de Vigotski, o grande público de intelectuais do campo da psicologia e da pedagogia fica com a sensação de desconhecimento sobre o pensamento desse autor, muito em função dos problemas de tradução dos seus textos em russo para outras linguas. A parte das edições estrangeiras dessas obras aconteceu durante o periodo de disputa ideológica entre EUA e URSS; e, mesmo em seu país, a produção cientifica de Vigotski foi retaliada pelo governo de Joseph Stalin. Hoje em dia, ainda há textos desse pensador que não foram publicados em russo. O presente artigo se pauta por um recorte teórico dentro da extensa produção acadêmica de Lev Vigotski. Este ensaio pretende discutir os conceitos de "vivência" nas obras de Vigotski. A palavra "vivência" é uma tradução para a língua portuguesa do vocábulo perejivanie, do idioma russo. Vigotski, em seus textos, também utiliza a palavra opit (experiência, em português), mas com um sentido distinto. A pesquisa defende que o conceito de "vivência" contribui para que os estudiosos da educação interpretem toda ação humana como portadora de uma certa atividade criativa.

Palavras-chave: Vigotski; vivência; atividade criadora.

\section{A look at the "experience" by its author: concepts and translations in the work of Vygotsky}

\begin{abstract}
Almost 80 years after Vygotsky's death, the great public of intellectuals in the field of psychology and pedagogy gets the feeling of ignorance about the thought of this author, much due to the problems of translating his texts in Russian into other languages. Part of the foreign editions of these works occurred during the period of ideological dispute between US and USSR; and even in his country, the scientific production of Vygotsky was retaliated by the government of Joseph Stalin. Nowadays, there are still texts of this thinker that have not been published in Russian. The present article is based on a theoretical cut within the extensive academic production of Lev Vygotsky. This essay aims to discuss the concepts of "experience" in Vygotsky's works. The word "experience" is a translation into the Portuguese language of the word perejivanie, from the Russian language. Vigotski, in his texts, also uses the word opit ("experience", in Portuguese), but with a different meaning. The research argues that the concept of "experience" contributes to education scholars interpret all human action as having a certain creative activity.
\end{abstract}

Keywords: Vygotsky; experience; creative activity.

\section{Introdução}

Lev Semionovich Vigotski foi um importante psicólogo bielorrusso que nasceu em 1896 e morreu em 1934. Ele fez parte de um grupo, ao lado dos intelectuais soviéticos A. R. Luria e A. N. Leontiev, que fundou a teoria Histórico-Cultural. Estes pesquisadores buscaram unir ontogênese e filogênese numa mesma escala histórica. Esta introdução é uma breve apresentação da vida e obra de Vigotski, que poderia ter sido tirada dos mais de 860.000 verbetes do Google em que aparece o nome deste autor. Mas acreditamos que poucas pessoas sabem sobre os pormenores acadêmicos da vida do intelectual bielorrusso. Os textos de Vigotski foram proibidos no seu país de origem por mais de 20 anos. A sua primeira reedição estrangeira aconteceu nos EUA, durante a Guerra Fria e, talvez por isso, o seu pensamento tenha sido tão lido, debatido e censurado no mundo ocidental capitalista.

Quase 80 anos depois da morte de Vigotski, o grande público de intelectuais do campo da psicologia e da pedagogia fica com a sensação de desconhecimento sobre pensamento desse autor, muito em função dos problemas de tradução dos seus textos em russo para outras línguas.

\footnotetext{
^Endereço para correspondência: Universidade Federal Fluminense, Instituto de Educação de Angra dos Reis, IEAR. Avenida do Trabalhador, 179, Verolme -

Angra dos Reis, RJ - Brasil. CEP: 23914-360.Email: daroberti@yahoo.com.br
}

A parte das edições estrangeiras dessas obras aconteceu durante o período de disputa ideológica entre EUA e URSS; e, mesmo em seu país, a produção científica de Vigotski foi retaliada pelo governo de Joseph Stalin. Hoje em dia, ainda há textos deste pensador que não foram publicadas em russo. São cerca de dez volumes que estão para serem traduzidos em diversas línguas.

O presente artigo se pauta por um recorte teórico dentro da extensa produção acadêmica de Lev Vigotski. Este ensaio pretende discutir os conceitos de perejivanie (vivência, em português) e opit (experiência, em português) e suas traduções do russo para o português. Buscamos entender o que alguns tradutores da obra de Vigotski chamaram de "experiência".

A professora Zoia Prestes (2010), que dedicou uma tese ${ }^{1}$ para compreender os conceitos de Vigotski vertidos para o português, nos informa que as primeiras traduções da palavra em russo perejivanie foram para as línguas inglesa (experience) e espanhola (experiência). Acreditamos que o significado da palavra perejivanie é muito mais complexo do que o vocábulo experiência e suas derivações para outras línguas, escolhido a título de interpretação das ideias de vigotskianas.

${ }^{1} \mathrm{O}$ título da tese é Quando não é quase a mesma coisa: análise de traduções de Lev Semionovitch Vigotski no Brasil-Repercussões no campo educacional. 


\section{As primeiras traduções de Vigotski no mundo e no Brasil}

Grande parte dos autores da teoria Histórico-Cultural foi perseguida pelo regime socialista soviético entre os anos 1920 e 1930 do século passado. Vigotski faleceu no ano de 1934; suas obras foram censuradas pelo governo de Stalin dois anos após sua morte. As pesquisas de Vigotski foram reeditadas na URSS e ao mesmo tempo nos EUA, no ano de 1955. Sendo assim, a primeira edição de um livro de Vigotski, fora da URSS, foi no Japão, em 1962, sob o título Shiko to genko, no mesmo ano em que é lançado Thought and language nos EUA, editado por John Wiley \& Sons (VIGODSKAIA; LIFANOVA, 1996, p. 411 apud PRESTES, 2010, p. 65-66).

No Brasil, o pensamento vigotskiano chega primeiro através de pesquisadores brasileiros que o citam a partir da obra Michlenie $i$ retch, editada nos EUA por John Wiley \& Sons, em 1962, e, em Portugal, pela Editora Antídoto no ano de 1979 (PRESTES, 2010, p. 66-67). Mas a primeira edição brasileira de um livro de Vigotski aconteceu somente no ano de 1987. Ele foi traduzido por Jefferson Luiz Camargo da versão inglesa de Michlenie $i$ retch para o português. A obra recebeu o título no Brasil de Pensamento e Linguagem. Zoia Prestes (2010, p. 67) comenta que a edição de 1987 cometeu uma "violência com a produção científica de um pensador" e talvez possa ser considerada uma das maiores "agressões" sofridas por uma obra de Vigotski.

O livro Pensamento e Linguagem, de 1987, sofreu uma série de modificações em seus capítulos, com supressão de citações, capítulos e páginas inteiras por parte dos editores. Prestes chega a denunciar uma certa censura num capítulo especial em que Vigotski tece críticas a Jean Piaget sobre os problemas do pensamento e da fala na infância. O capítulo original do russo tinha 54 páginas, e a versão inglesa ficou com apenas 19 páginas. Os comentários de Piaget, que aparecem na obra em russo, desapareceram na tradução para o inglês. O professor Newton Duarte (2004, apud PRESTES, 2010, p. 68), que faz parte de um grupo de críticos das traduções e apropriações indevidas do pensamento de Vigotski no Brasil, fez uma interessante observação sobre a atualização do pensamento do escritor soviético:

[...] Se as 'discussões polêmicas' foram consideradas de 'pouco interesse para o leitor contemporâneo', então a cada nova edição o texto de Vigotski deveria ser 'atualizado'? Os textos de todos os autores clássicos, de séculos passados, deveriam ser atualizados constantemente? O leitor não tem o direito de decidir por si mesmo o que lhe interessa ou não no texto de um determinado autor?

A produção científica de Vigotski sofreu deturpações e censuras em diversas línguas em que suas obras foram traduzidas. Mesmo em seu país de origem, seus trabalhos foram proibidos por mais de 20 anos.

\section{Mas o que é traduzir?}

A professora Zoia Ribeiro Prestes (2010), em pesquisa de doutorado, propôs investigar a atividade de tradução em meio às obras do professor Lev Vigotski publicadas em português. A pesquisadora encontrou uma série de equívocos nas traduções do russo para o português, inglês e espanhol. Para a nossa investigação, a relevância dessa tese decorre de ela discutir como se dá o ato de traduzir e a opção que os tradutores fizeram pelo conceito de "experiência" no lugar do original em russo, perejivanie.

Prestes (2010, p. 88) acredita que não exista uma posição "unânime" entre os estudiosos do assunto sobre o que seja a tradução, mas sim dois tipos de encaminhamentos teórico-metodológicos que seguem direções opostas. Eles são divididos entre aqueles que enxergam a atividade como facilitadora do acesso do povo estrangeiro à cultura de um país distante e os que "menosprezam" a função, creditando à aprendizagem da língua a melhor forma para compreender os escritos originais. A autora ainda discute a diferença entre tradução literária e científica, apontando que a última deve ser realizada por um profissional estudioso da ciência a ser vertida.

Alheio a essa discussão, mas nem tanto, ${ }^{2}$ Vigotski acredita que a tradução é uma atividade criadora ou combinatória, ${ }^{3}$ porque o tradutor, através da sua experiência, ou seja, do acesso ao acervo cultural de que dispõe, apresenta a possibilidade de criar. Para o autor bielorrusso, quanto maior a "experiência" que o tradutor tem, maior a sua capacidade de criar. Traduzir e criar são atividades homônimas para Vygotsky (VYGOTSKY; LURIA, 1996, p. 14), segundo o qual o cérebro (humano) "não é apenas o órgão que conserva e reproduz nossa 'experiência' anterior, mas também o que combina e reelabora, de forma criadora, elementos da "experiência" anterior, erigindo novas situações e novo comportamento". ${ }^{4}$

\section{Experiência e/ou vivência em Vigotski ${ }^{5}$}

A nossa pesquisa se preocupou em compreender os conceitos de "experiência" e "vivência" nas obras de Vigotski; para isso, os textos e livros da sua bibliografia mais consultados foram: Voobrajenie e tvortchestvo $v$ detskom vozraste (Imaginação e criação na infância [VIGOTSKI, 2009]), Etiudi po istorii povedenia. Obeziana, Primitiy. Rebionok (Estudos sobre a história do comportamento: o macaco, o primitivo, a criança [VIGOTSKI; LURIA, 1996]), Krizis semi liet (A crise dos sete anos [VIGOTSKI, 2006a]), Psirrologuia iskusstva (Psicologia da arte [VIGOTSKI, 1999]) e Problema sredi v pedologuii (Quarta aula: a questão do meio na pedologia [VINHA; WELCMAN, 2010]). Para entendermos a complexidade de "experiência" e "vivência" no

\footnotetext{
${ }^{2}$ Prestes cita o especialista em tradução Octávio Paz, que, assim como Vigotski, acredita na tradução como atividade de verter do original a nova língua, originando o poder de criação.

${ }^{3}$ Tomasello (2003) toma essa capacidade ontológica do sujeito de fazer parte e apropriar-se da cultura humana como "efeito catraca", e Corsaro (2011) discute essa mesma ideia dentro do conceito de reelaboração interpretativa. Aliás, tem um texto interessante da professora Zoia Prestes (2013) que contribui para elucidar os diferentes ou semelhantes pontos de vista entre a Sociologia da Infância, no qual Corsaro se envolve, e a teoria Histórico-Cultural, de que Vigotski fez parte.

${ }^{4} \mathrm{Em}$ sua tese, a professora Zoia Prestes (2010, p. 77) apresenta uma citação muito parecida com esta, retirada do livro Voobrajenie e tvortchestvo $v$ detskom vozraste (Imaginação e criação na infância [VIGOTSKI, 2009]).

"O termo "vivência" (em russo perejivanie) foi traduzido no Brasil pelo professor Paulo Bezerra (VIGOTSKI, 2001) como emoção e sentimento, e em inglês por experience (experiência, em português) (MINICK, 1987).
} 
pensamento de Vigotski, acreditamos na premissa de que podemos estudar, ao mesmo tempo, os conceitos vigotskianos de "material" e "forma".

Vigotski (1999), no livro Psicologia da Arte, discute a relação entre "material" e "forma" nos diversos gêneros literários. Os dois conceitos são elementos básicos que se encontram dentro da produção literária. Segundo o professor bielorrusso, "material" é um conceito que serve como base, estrutura ou suporte para a atividade criativa. O escritor de obras literárias usa as relações cotidianas, "experiências" e o ambiente social, ou seja, o que existia antes da sua criação artística e vai continuar existindo, independente dela (VIGOTSKI, 1999). A “forma" tem a ver com o ato criativo do narrador de organizar esse "material" com a intenção de provocar uma reação estética no leitor.

Não é à toa que Vigotski defende o protagonismo da criação artística em relação ao usuário e do próprio autor da obra de arte, e para isso ele coloca em relevo as palavras "mínimo" e "forma" ao longo da sua pesquisa. Vigotski (1999, p. 42) elucidou a relação entre "mínimo" e "forma" quando disse que

[...] a diferença entre um regente genial e um medíocre na execução da mesma peça musical, a diferença entre um pintor genial e um copiador absolutamente preciso de seu quadro resume-se inteiramente a esses elementos infinitamente pequenos da arte, que pertencem à correlação dos seus componentes, isto é, aos elementos formais. A arte começa onde começa o mínimo, e isto equivale a dizer que a arte começa onde começa a forma.

Portanto, as palavras "mínimo" e "forma" são usadas como sinônimas no livro Psicologia da arte (VIGOTSKI, 1999). ${ }^{7}$ Elas são categorias que se sobressaem na análise da produção artística. Toda a criação na arte tem uma estrutura e uma lógica própria que a explica. Vigotski, com o uso dessas categorias, quis dizer que os artistas e os apreciadores de arte compartilham dos mesmos acontecimentos sociais e contexto histórico da produção artística, por isso ele defende que a obra de arte ganha vida e se desprende do processo criativo. ${ }^{8}$

Perejivanie (vivência, em português) é uma palavra relevante para a teoria Histórico-Cultural. Há relatos (PRESTES, 2010) de que este conceito científico provocou um embate epistemológico entre Leontiev e Vigostki. Este definiu "vivência" como:

\footnotetext{
${ }^{6}$ Vigotski (1999) usa os termos "fábula" e "enredo" como sinônimos, respectivamente, de "material" e "forma" ao longo do livro Psicologia da arte.

${ }^{7}$ Neste livro aparece uma história narrada por Tolstói sobre o pintor Briulov que nos ajuda a entender a relação do "mínimo" na obra de arte: "ao corrigir o estudo de um aluno, Briulov deu um leve toque em algumas partes, e o estudo ruim e morto de repente ganhou vida. 'Vejam, bastou um mínimo toque e tudo mudou', disse um dos alunos. A arte começa onde começa esse mínimo, disse Briulov" (VIGOTSKI, 1999, p. 41)

${ }^{8}$ Vigotski, ao longo do seu livro, explica que o processo de criação artística envolve o que ele chamou de "o social em nós", ou seja, o artista e o apreciador da produção artística compartilham todo o contexto histórico e social da produção artística. Vigotski propôs estudar a fábula em sua pesquisa e identificou algumas caraterísticas gerais que sempre aparecem neste gênero literário. Por exemplo, o fabulista (artista) escolhe determinado animal como personagem na história, a partir de suas características psicológicas. É a raposa considerada um animal astuto e rápido ou o corvo que aparece como um bicho de aspecto desagradável. A fábula só tem a capacidade de contar o seu enredo, porque o autor e o seu leitor já conhecem esses perfis psicológicos previamente. A força da fábula se encontra na falta de necessidade em explicar as características comportamentais dos "personagens-animais" literários.
}

uma unidade na qual, por um lado, de modo indivisível, o meio, aquilo que se vivencia está representado - a vivência sempre se liga àquilo que está localizado fora da pessoa - e, por outro lado, está representado como eu vivencio isso, ou seja, todas as particularidades da personalidade e todas as particularidades do meio são apresentadas na vivência, tanto aquilo que é retirado do meio, todos os elementos que possuem relação com dada personalidade, como aquilo que é retirado da personalidade, todos os traços de seu caráter, traços constitutivos que possuem relação com dado acontecimento. Dessa forma, na vivência, nós sempre lidamos com a união indivisível das particularidades da personalidade e das particularidades da situação representada na vivência (VIGOTSKI, 1999, p. 686).

A leitura que Leontiev (2007) fez do conceito de perejivanie leva a crer que o pensamento de Vigostki segue uma base epistêmica interacionista. A. N. Leontiev acredita que o ambiente social e as peculiaridades do indivíduo entram em interação, mas mantêm uma relação de independência um com outro. Acreditamos que Vigotski não entendia perejivanie dessa forma, e o cerne da questão, para a compreensão desse conceito, passa pela tal relação, antes descrita, de independência entre ambiente social e particularidade do sujeito. "Unidade" é um dos conceitos-chave do pensamento de Vigotski. "Unidade" é um conceito que se relaciona diretamente com o de perejivanie e que nos ajudou a compreender uma certa contradição na crítica de Leontiev à Vigotski.

[...] Pero precisamente a causa de que la personalidad representa una unidad y actúa como un todo único, destaca desigualmente en el desarrollo unas u outras funciones, diversas y relativamente independientes entre sí. Estas tesis - la diversidade de funciones relativamente independentes en el desarrollo y la unidad de todo el processo de desarrollo de la personalidade - no solo no se contradicen, sino, como demonstró Stern, se condicionan mutuamente. [...] Lo mismo que la personalidade, el intelecto representa, sin duda alguna, un todo único, pero una unidad estrutural homogênea y simples, sino diversa e compleja (VIGOTSKI, 2006b, p. 23-24).

Neste trecho, Vigotski explica a relação simples e ao mesmo tempo diversa entre a construção da personalidade e o desenvolvimento das funções motoras do corpo. Assim como "unidade", "vivência" é esse todo único, homogêneo, mas complexo e independente entre si. "Vivência" é essa relação de "unidade", ao mesmo tempo independente e inseparável do sujeito e do meio social. Por isso, não é uma relação de interação, como afirmava Leontiev; não existe meio em absoluto sem a presença do indivíduo que o interprete (PRESTES, 2010).

Perejivanie e "unidade" são conceitos que devem ser discutidos conjuntamente, assim como o de "forma", que, como já dissemos, faz parte do pensamento vigotskiano. Acreditamos que a "vivência" (ou forma) é o uso consciente da "experiência" (ou material), acumulada pelo sujeito, como ato criativo do novo no mundo. Agora, aprofundaremos o conceito de "experiência" em Vigotski.

Opit (experiência, em português) é uma palavra completamente diferente de perejivanie em russo. O professor Holbrook Mahn (2007 apud PRESTES, 2010) discute 
que não existe uma palavra em inglês que possa traduzir perejivanie, mas opit pode ser vertido do russo para o inglês com o uso da palavra experience.

Opit é um conceito do campo da psicologia que não foi criado por Vigotski e nem pelo grupo de estudiosos da teoria Histórico-Cultural. Vigotski (2004) discute um pouco esse termo em sua obra Pedagoguitcheskaia psirrologuia (Psicologia Pedagógica). É um livro em que o autor bielorrusso propõe estudar a psicologia em meio às práticas educacionais que contribuiriam para o desenvolvimento de uma nova sociedade socialista soviética. Vigotski discute o surgimento da psicologia positivista contrária às propostas teóricas da psicologia metafísica. A psicologia positivista ou empírica se baseava na "experiência".

A professora Zoia Prestes (2010) relata que, no livro Imaginação e criação na infância, Vigotski discute a importância da brincadeira para a criança, pois, segundo ele, é nesta situação que ela aprende as regras sociais que estão presentes na vida real. Quando a criança brinca de imitar um adulto, ela não reproduz por completo cada ato, comportamento e atitude deste adulto. A criança cria, numa brincadeira de imitar. Ela coloca a sua marca de criação, combinando situações da realidade e sua "experiência". A palavra "experiência" aparece novamente na teoria de Vigotski. Mas que "experiência" é essa de que o autor fala?

Acreditamos que o conceito de "experiência", dentro do pensamento de Vigotski, leva em conta o processo de quantificação numa escala linear de amadurecimento do indivíduo ao longo do seu processo histórico. A "experiência" é uma atividade acumulativa em que o sujeito mais experiente é aquele que está mais avançado (mais velho) nas fases do desenvolvimento humano. O conceito de "experiência" pode ser vinculado ao de "material". Para Vigotski, "material" é um dos suportes que constituem a atividade de criação humana. Assim como "experiência", "material" fornece subsídios sociais para a criação humana; a partir desses elementos da história pregressa do homem, o indivíduo aumenta a sua gama de possibilidades de interpretar, combinar e criar algo novo no mundo.

\section{Conclusão}

Este ensaio apresenta avanços e limites na discussão da teoria de Vigotski. Os avanços ficaram em torno de desmistificar a visão interacionista da teoria de Vigotski; invólucro que encapsulou o pensamento desse autor, tanto no seu país de origem como nas traduções de seus textos para o mundo ocidental. Apresentamos a história das traduções do conceito de perejivanie em português e propusemos um renovado debate à luz da "unidade" dos conceitos vigotskianos em prol do desenvolvimento de um novo conhecimento sobre a palavra perejivanie.

Os limites do artigo apontam para a necessidade de sairmos da "zona de estabilidade" em que se encontra o significado da palavra "vivência", dentro do pensamento de Vigotski. Significado e sentido para o pensador bielorrusso não são a mesma coisa. "O sentido da palavra é sempre complexo, e possui várias zonas de estabilidade diferentes. O significado é somente uma das zonas daquele sentido que a palavra adquire no contexto de al- guma fala e, além do mais, uma zona mais estável, mais unificada e precisa" (VIGOTSKI, 1999, p. 328 apud PRESTES, 2010, p. 81). Buscamos um novo sentido para "vivência" em que possamos ao mesmo tempo criar e explicar a realidade à nossa volta.

\section{Referências}

CORSARO, William A. Sociologia da infância. São Paulo: Penso, 2011.

LEONTIEV, Alexis Nikolaevich (Org.). Slovar L. S. Vigotskogo. Moska: Smisl, 2007.

MINICK, Norris. Implications of Vygotsky's theories for dynamic assessment. In: LIDZ, Carol S. (Ed.). Dynamic assessment: an interactional approach to evaluating learning potential. New York: Guilford, 1987. p. 116-140.

PRESTES, Zoia Ribeiro. Quando não é quase a mesma coisa: análise de traduções de Lev Semionovitch Vigotski no Brasil - Repercussões no campo educacional. 2010. 295 f. Tese (Doutorado em Educação)-Faculdade de Educação, Universidade de Brasília, Brasília, 2010. Disponível em: http:// repositorio.unb.br/handle/10482/9123. Acesso em: $12 \mathrm{dez}$. 2018.

PRESTES, Zoia Ribeiro. A sociologia da infância e a teoria histórico-cultural: algumas considerações. Revista de Educação Pública, Cuiabá, v. 22, n. 49, p. 295-305, 2013.

TOMASELLO, Michael. Origens culturais da aquisição do conhecimento humano. Tradução de Claudia Berliner. São Paulo: Martins Fontes, 2003.

VIGOTSKI, Lev Semionovitch. Pensamento e linguagem. Tradução de M. Resende. Lisboa: Antídoto, 1979.

VIGOTSKI, Lev Semionovitch. Pensamento e linguagem. São Paulo: Martins Fontes, 1987.

VIGOTSKY, Lev Semionovitch. Psicologia da Arte. Tradução de Paulo Bezerra. São Paulo: Martins Fontes, 1999.

VIGOTSKI, Lev Semionovitch. A construção do pensamento e da linguagem. Tradução de Paulo Bezerra. São Paulo: Martins Fontes, 2001.

VIGOTSKI, Lev Semionovitch. Psicologia Pedagógica. São Paulo: Martins Fontes, 2004.

VIGOTSKI, Lev Semionovitch. La crisis de los siete años. Madri: Machado Libros, 2006a. Obras Escogidas, t. 4, p. 11-40.

VIGOTSKI, Lev Semionovitch. Introduccion: los problemas fundamentales de la defectologia contemporánea. Madri: Machado Libros. 2006b. Obras Escogidas, t. 5, p. 377-386.

VIGOTSKI, Lev Semionovitch. Imaginação e criação na infância. Tradução de Zoia Prestes. São Paulo: Ática. 2009.

VYGOTSKY, Lev Semionovitch.; LURIA, Alexander Romanovich. Estudos sobre a história do comportamento: o macaco, o primitivo e a criança. Porto Alegre: Artes Médicas, 1996.

VINHA, Márcia Pileggi; WELCMAN, Max. Quarta aula: a questão do meio na pedologia, Lev Semionovich Vigotski. Psicol. USP, São Paulo, v. 21, n. 4, p. 681-701, 2010. Cross ${ }^{\text {Ref. }}$

Recebido em: 19 de fevereiro de 2016 Aceito em: 16 de janeiro de 2019 